\title{
Is the All-Subjected Principle Extensionally Adequate?
}

\author{
Vuko Andrić ${ }^{1,2}$ \\ Published online: 6 October 2020 \\ (c) The Author(s) 2020
}

\begin{abstract}
This paper critiques the All-Subjected Principle. The All-Subjected Principle is one of the most prominent answers to the Boundary Problem, which consists in determining who should be entitled to participate in which democratic decision. The AllSubjected Principle comes in many versions, but the general idea is that all people who are subjected in a relevant sense with regard to a democratic decision should be entitled to participate in that decision. One respect in which versions of the All-Subjected Principle differ concerns how to best understand 'subjectedness'. One view spells out 'subjectedness' in terms of legal bindingness. Another view understands 'subjectedness' in terms of coercion. I argue that the All-Subjected Principle is extensionally inadequate on both views in that it yields verdicts that are at odds with our considered judgements about certain cases. These cases involve legal norms of referral or international administrative assistance.
\end{abstract}

Keywords All-Subjected Principle · Boundary Problem · Legal bindingness · Coercion · Legal norms of referral · International administrative assistance

This paper examines the All-Subjected Principle, which is one of the most prominent answers to the Boundary Problem. The Boundary Problem consists in determining who should be entitled to participate in which democratic decision. According to the All-Subjected Principle, entitlements to participation in democratic decisions should depend on subjectedness.

Many different versions of the All-Subjected Principle can be found in the literature on the Boundary Problem. The versions differ, among other things, in how they spell out 'subjectedness'. One view focuses on legal bindingness, the other on coercion. In this paper, I argue that the All-Subjected Principle is extensionally inadequate on both views. An answer to the Boundary Problem is (fully) extensionally adequate if and only if the answer coheres with our considered judgements

Vuko Andrić

Vuko.Andric@uni-bayreuth.de

1 Institut für Philosophie, Universität Bayreuth, Universitätsstraße 30, 95440 Bayreuth, Germany

2 Institute for Futures Studies, Box 591, Stockholm 10131, Sweden 
regarding democratic inclusion (and exclusion) in particular cases, i.e. our considered judgements about who should (and who should not) be entitled to participate in the democratic decisions that feature in (real or hypothetical) cases. I present cases that attempt to show that democratic inclusion should neither depend on legal bindingness nor on coercion.

In the first section, I introduce the Boundary Problem and the All-Subjected Principle. In the second section, I review the current debate about the extensional adequacy of the All-Subjected Principle and, in this context, defend the All-Subjected Principle against two objections that have been put forward in the literature. In the third section, I try to show, by presenting a kind of case that has so far been ignored in the literature, that versions of the All-Subjected Principle that understand subjectedness in terms of legal bindingness are extensionally inadequate. In the fourth section, I argue, by means of a modified version of the case presented in the third section, that versions of the All-Subjected Principle that focus on coercion are extensionally inadequate, too. In the fifth section, I address an objection, which is based on an alternative interpretation of the All-Subjected Principle. In the sixth section, I summarize my findings and comment on their significance.

\section{The Boundary Problem and the All-Subjected Principle}

The All-Subjected Principle is a prominent answer to the Boundary Problem. The Boundary Problem consists in finding a convincing answer to the following question:

BP

Who should be entitled to participate in which democratic decision-making? ${ }^{1}$

BP comes up, e.g., in the case of resident aliens and expatriates (Beckman 2006, 2014; López-Guerra 2005). Should resident aliens be entitled to vote in elections in their host countries? Should expatriates be entitled to vote in elections in their home countries $?^{2}$

\footnotetext{
${ }^{1}$ The problem is called 'the boundary problem' by Whelan (1983, p. 13). Other labels are "the problem of inclusion" (Dahl 1989, p. 119), 'the problem of the unit' (Dahl 1989, p. 193) and 'the problem of constituting the demos' (Goodin 2007, p. 40).

${ }^{2}$ BP also looms large in other issues such as the legitimacy of border regimes (Abizadeh 2008, 2010; Miller 2010), the democratic representation of future generations (Beckman 2013; Tännsjö 2007) and the justification of global democracy (Agné 2010; Miller 2009; List and Koenig-Archibugi 2010; Andrić 2017).
} 
Many different formulations of the All-Subjected Principle, which often amount to different versions, can be found in the literature. ${ }^{3}$ In this paper, I distinguish two basic versions:

\section{ASP}

A person should be entitled to participate in a democratic decision if and only if the person is subject to the decision. ${ }^{4}$

\section{$A S P *$}

A person should be entitled to participate in a democratic decision if and only if the decision is made by a state to whose decisions the person is normally subject. 5

In this and the following three sections, I focus on ASP. The fifth section deals with ASP*.

ASP comes in several versions, which differ regarding their criterion for what it takes to be subject to a democratic decision. Two basic views about how to understand 'subjectedness' can be found in the literature on the boundary problem and lead to different versions of ASP. ${ }^{6}$ According to the first version,

$A S P_{L}$

A person should be entitled to participate in a democratic decision if and only if the person is legally bound by the decision.

According to the second version,

$$
A S P_{C}
$$

\footnotetext{
3 Proponents of the All-Subjected Principle include Abizadeh (2012), Beckman (2006, 2008, 2009, 2013, 2014), Cohen (1998, p. 223, n. 1), Dahl (1989), Erman (2014), Habermas (1998), López-Guerra (2005), Miller (2009) and Owen (2012). Let us consider some formulations of the All-Subjected Principle that can be found in the literature. A classic formulation by Robert A. Dahl reads as follows: 'Every adult subject to a government and its laws must be presumed to be qualified as, and has an unqualified right to be, a member of the demos', Dahl (1989, p. 127). Claudio López-Guerra writes that 'all individuals who live permanently under the laws and binding decisions of the polity should be included', López-Guerra (2005, p. 222). Ludvig Beckman's more recent formulation of the All-Subjected Principle has it that 'anyone bound by a legal rule is a subject, in the sense pertinent to democratic rights', Beckman (2014, p. 256). Eva Erman states the principle in its general form as requiring 'that all those who are subjected to the laws, i.e., those whose actions are governed by them, should have a say in their making', Erman (2014, p. 538). Arash Abizadeh maintains 'that all those subjected to the exercise of political power be included in the demos, i.e., granted a right of democratic say over political decisions', Abizadeh (2012, p. 878). David Miller states that a democracy's 'domain should extent to include all those who will be coerced by its decisions' and that 'being coerced by a demos does generate a claim for inclusion', Miller (2009, pp. 214 and 225).

${ }^{4}$ Notice that some of the quotes provided in the previous footnote suggest a formulation of ASP without the 'and only if' part. However, such a formulation would even increase ASP's problems with over-inclusiveness that I press in this paper.

5 What I said in the previous footnote about the 'and only if' phrase with regard to ASP also applies, mutatis mutandis, to ASP*.

${ }^{6}$ On combinations of the basic versions, see Beckman (2014) and Goodin (2016).
} 
A person should be entitled to participate in a democratic decision if and only

if the person is exposed to coercion by the state that implements the decision.

What can be said in favour of $\mathrm{ASP}, \mathrm{ASP}_{\mathrm{L}}$ and $\mathrm{ASP}_{\mathrm{C}}$ ? One important argument appeals to understanding democracy in terms of autonomy, self-rule or self-government (differences between these concepts can be ignored for our purposes). In this vein, López-Guerra claims that 'if democrats endorse the ideal of self-government, anyone who is subject to the laws of a democratic polity should be included in the citizen body' (López-Guerra 2005, p. 219). Likewise, Abizadeh argues that 'democratic self-rule means that the exercise of political power conforms to the collective will of those subjected to it, and why the scope-condition of democratic legitimacy is that all those subject to the exercise of political power have a right of democratic say' (Abizadeh 2012, p. 878). Prima facie, I find the kind of argument put forward by Abizadeh and López-Guerra promising and will come back to it at several points.

A second kind of argument for ASP appeals to its alleged extensional adequacy. This is the main focus of the next sections, where I argue that, although $\mathrm{ASP}_{\mathrm{L}}$ and $\mathrm{ASP}_{\mathrm{C}}$ can be defended against some objections that concern extensional adequacy, $\mathrm{ASP}_{\mathrm{L}}$ and $\mathrm{ASP}_{\mathrm{C}}$ eventually fail because they are extensionally inadequate.

\section{Extensional Adequacy and ASP}

The argument from extensional adequacy for ASP appeals to the presumably plausible solutions ASP yields for instances of BP. The standards of plausibility are provided by our considered judgements regarding democratic inclusion in particular cases. The methodological background of the argument is some kind of reflective equilibrium or coherentism: the assumption that normative principles like ASP need to cohere with our considered judgements about particular cases as well as with our general normative and factual beliefs (cf. Daniels 2018).

A terminological remark. In what follows I will speak about "widespread judgements' when I refer to what people in fact think (or what I take them to think) and about 'our considered judgements' when, in addition, I state reasons for thinking that the judgements are correct. An answer to BP is extensionally inadequate to the extent that it does not cohere with our considered judgements about democratic inclusion, and an answer to BP risks being extensionally inadequate to the extent that it does not cohere with widespread judgements about democratic inclusion.

The argument from extensional adequacy for ASP can be illustrated by comparing the judgements implied by ASP with the verdicts yielded by the main competitor of ASP — the All-Affected Principle, according to which

$A A P$

A person should be entitled to participate in a democratic decision if and only if the person is affected by the decision in a relevant way. ${ }^{7}$

\footnotetext{
7 Proponents of AAP include Arrhenius (2005, 2018, 2019), Brighouse and Fleurbaey (2010), Cohen (1971), Dahl (1970), Goodin (2007), Shapiro (1999, 2012) and Young (2000).
} 
There are different versions of AAP, which yield different verdicts regarding instances of BP. For the sake of brevity, let us focus on what is perhaps the most influential version of AAP: the possibilist version defended by Robert Goodin, According to Goodin, 'this version requires us to include in the demos every interest that might possibly be affected by any possible decision arising out of any possible agenda' (Goodin 2007, p. 59). Tweaking Goodin's formulation a bit, ${ }^{8}$ the possibilist version of AAP can be formulated as follows:

\section{$A A P_{P}$}

A person should be entitled to participate in a democratic decision if and only if the person could be made better off or worse off by any alternative available in that decision relative to how well or badly off the person could be on any other alternative, including alternatives that were not on the agenda.

But is not almost every person affected by almost any decision in the sense of $\mathrm{AAP}_{\mathrm{P}}$ ? Goodin confirms this suspicion and claims 'that (at least in principle) we should give virtually everyone a vote on virtually everything virtually everywhere in the world' (Goodin 2007, p. 63). However, this implication, though embraced by Goodin, strikes many theorists as too inclusive (e.g. Miller (2009, p. 215), Song (2012, p. 50), and Andrić (2017, Sect. 2)). It is at odds with widespread judgements and practices regarding democratic inclusion. It is an open question, e.g., if resident aliens should be entitled to vote in their host countries. But we take it for granted that persons who are not citizens of a state and reside outside that state should not be entitled to participate in the elections of this state. ${ }^{9}$ Therefore, $\mathrm{AAP}_{\mathrm{P}}$ risks being extensionally inadequate: it fails to deliver verdicts that cohere with widespread judgements regarding democratic inclusion.

At first glance, ASP seems to fare better in this regard. $\mathrm{ASP}_{\mathrm{L}}$ seems to imply that resident aliens should be entitled to participate in decisions in their host countries because they are legally bound by the decisions taken there. But $\mathrm{ASP}_{\mathrm{L}}$ does not seem to imply that non-citizens who reside outside a country should normally be entitled to participate in elections in that country. ${ }^{10}$ Since they reside outside the country, the democratic decisions made in the country normally do not seem to bind them legally. Likewise, on $\mathrm{ASP}_{\mathrm{C}}$, resident aliens are exposed to coercion by their host countries. But persons who reside outside a foreign country normally do not seem to be exposed to coercion by that country. The upshot is that ASP, unlike $\mathrm{AAP}_{\mathrm{P}}$, seems to be extensionally adequate insofar as it avoids the kind of over-inclusiveness that haunts $\mathrm{AAP}_{\mathrm{P}}$.

However, on closer examination, ASP is faced with two problems regarding its extensional adequacy. The first problem is that ASP seems to imply, implausibly,

\footnotetext{
${ }^{8}$ Notice that the term 'decision' as Goodin uses it in the foregoing quote does not refer to a choice between different alternatives but rather to an alternative.

9 By 'we', I do not mean all persons. Obviously, Goodin is not one of 'us' in the sense that I am using 'we'. Rather, 'we' has to be understood in the context of the coherentist framework that I assume in this paper and that I sketched at the outset of this section as referring to all and only those persons who share the widespread judgements and practices in question.

${ }^{10}$ I am ignoring the special issue of border regimes, see Abizadeh (2008) and Miller (2010).
} 
that transients should have voting rights in their host countries (see Goodin (2007, p. 42) and Dahl (1989, p. 128)). If a tourist happens to be in a country while the host country is having national elections, ASP seems to imply that the tourist should be entitled to vote in these elections. For tourists are bound by the laws of their host countries and exposed to sanctions if they do not comply with these laws.

Defenders of ASP have suggested solutions for the problem of transients. ${ }^{11}$ In this paper, I will not try to evaluate these solutions. Rather, I want to point out that the problem of transients is a problem for any proposed solution to BP. It is a problem not only for ASP but also for AAP, because transients are affected by the decisions made in their host countries. But it is also a problem for any other prima facie plausible solution to BP because, even though transients should all things considered plausibly not be entitled to participate in elections in their host countries, there are also considerations that (pro tanto) speak in favour of giving them the vote for such elections. After all, democracy is self-government-every person who is governed should, ideally, also be able to participate in the governing. And transients are governed in their host countries, albeit only for a very short time. The upshot is that it does not speak against ASP, as compared to other answers to BP, if the problem of transients has not been solved yet.

The second problem $\mathrm{ASP}_{\mathrm{L}}$ is faced with is also a problem of over-inclusiveness. Goodin points out that many states claim authority to make laws that apply to every person, even to non-citizens who reside abroad, and argues that universal jurisdiction means that non-citizens abroad are subject, in the sense of $\mathrm{ASP}_{\mathrm{L}}$, to these laws (Goodin 2016). It therefore seems that, if $\mathrm{AAP}_{\mathrm{P}}$ is too inclusive, then so is $\mathrm{ASP}_{\mathrm{L}}$.

This is also a problem for $\mathrm{ASP}_{\mathrm{C}}$ if we assume that being exposed to coercion by a state via law coincides with being bound by that law. Goodin offers a profound analysis of the possibilities to avoid this coincidence and argues that every possibility results in problems of over- or under-inclusiveness for $\mathrm{ASP}_{\mathrm{C}}$. While I am sympathetic to this argument, I will, for brevity's sake, not examine it here and only argue that $\mathrm{ASP}_{\mathrm{L}}$ can be defended in a different way against Goodin's claim that $\mathrm{ASP}_{\mathrm{L}}$ is in the same boat as $\mathrm{AAP}_{\mathrm{P}}$ as far as over-inclusiveness is concerned. If $\mathrm{ASP}_{\mathrm{L}}$ can be defended against this claim, then so can $\mathrm{ASP}_{\mathrm{C}}$ - at least those versions of $\mathrm{ASP}_{\mathrm{C}}$ that are co-extensive with $\mathrm{ASP}_{\mathrm{L}}$, i.e. the versions on which a person is exposed to coercion just in case the person is legally bound.

Here is the defence. I submit that $\mathrm{ASP}_{\mathrm{L}}$ delivers the correct results in cases of universal jurisdiction. For if a state makes laws that apply to non-citizens abroad, then denying those non-citizens a say with regard to the laws amounts to a heteronomous relation in which the non-citizens are governed without participating in the governing. This constellation is at odds with the idea that democracy is selfgovernment of the people.

But does this not mean that $\mathrm{ASP}_{\mathrm{L}}$ is just as inclusive as $\mathrm{AAP}_{\mathrm{P}}$ ? It does not. States can simply refrain from making laws that apply to every person. This would solve

\footnotetext{
11 Suggestions can be found, e.g. in Beckman (2009), Dahl (1998), Erman (2014), López-Guerra (2005) and Owen (2012). In fact, Erman's and Owen's solutions are built on an alternative understanding of the All-Subjected Principle, namely ASP*, which I reject in the fifth section.
} 
the problem for $\mathrm{ASP}_{\mathrm{L}} \cdot{ }^{12} \mathrm{By}$ contrast, virtually any law a state makes will affect, in the sense of $\mathrm{AAP}_{\mathrm{P}}$, every person. This is why the over-inclusiveness objection cannot be rebutted for $\mathrm{AAP}_{\mathrm{P}}$ by a similar manoeuvre. On $\mathrm{AAP}_{\mathrm{P}}$, states cannot escape the need for universal inclusion even by making no laws at all. This is because of the laws that states could make.

Notice, finally, that universal jurisdiction without universal inclusion, while at odds with the ideal of democracy, is not necessarily wrong all things considered. For the ideal of democracy might conflict with other ideals, and these other ideals could all things considered justify universal jurisdiction without universal inclusion. However, even if this were the case, there would be democratic costs, as $\mathrm{ASP}_{\mathrm{L}}$ rightly points out.

The bottom line is that the objections that have been raised in the literature regarding the extensional adequacy of ASP fail. By contrast, I will argue that the problems that I am going to develop for $\mathrm{ASP}_{\mathrm{L}}$ and $\mathrm{ASP}_{\mathrm{C}}$ in the next two sections, respectively, decisively speak against these principles.

\section{Against $\mathrm{ASP}_{\mathrm{L}}$}

The following case demonstrates that $\mathrm{ASP}_{\mathrm{L}}$ is extensionally inadequate:

\section{Bureaucracia and Lazyland}

Bureaucracia is a country with a detailed body of traffic regulations, called the Traffic Law, which regulates on which side of the road to drive, what the traffic signs have to look like and so on. Lazyland is a country in which the traffic laws of Bureaucracia are held in high esteem. In order to save time, money and manpower, Lazyland does not bother to make substantial laws in this area of legislation but simply adopts a legal norm of referral that gives legal force to the traffic laws of Bureaucracia in Lazyland. Lazyland's Law of Traffic Rules simply states that Bureaucracia's Traffic Law is valid in Lazyland. One day, Bureaucracia is going to make a decision about a change in its Traffic Law, namely to adopt a speed limit on highways. The people of Lazyland are strongly opposed to this idea and would like to vote against it. $^{13}$

To keep things simple, I make the following assumptions: all citizens of Bureaucracia reside within Bureaucracia; there are no children, persons with mental

\footnotetext{
12 Since a solution to BP is a function with two variables (persons and democratic decisions), a democratically permissible arrangement can be reached by holding the enfranchised persons fixed and restrict the range of issues over which democratic decisions are made. Cf. Goodin's (2007, p. 66) remark on the 'decisional power' of demoi and the remarks on the 'scope' of democracy by Arrhenius (2018, p. 93, 2019), Dahl (1989, pp. 207, 209) and Miller (2009). This is the background for my defence regarding $\mathrm{ASP}_{\mathrm{L}}$ and universal jurisdiction. Simply put, states (or other entities) can restrict democratic decisions such that only a fixed set of persons are bound by them.

${ }^{13}$ Real-life examples of legal norms of referral are so-called enforcements of foreign judgements; see, e.g. Campbell (1997).
} 
impairments or felons among these citizens; every person residing in Bureaucracia is also a citizen of Bureaucracia. Mutatis mutandis for Lazyland. ${ }^{14}$

Most people, I assume, would intuitively judge that the people of Bureaucracia-the Bureaucracians - should be entitled to decide about the speed limit without including the people of Lazyland-the Lazylanders-in the decision. This judgement qualifies as a considered judgement because it finds support in the platitude that democracy is government of the people by the same people. The decision classifies as an act of government of and by the people of Bureaucracia. In virtue of Lazyland's Law of Traffic Rules, any decision about Bureaucracia's Traffic Law will be binding for the Lazylanders. ${ }^{15}$ But this is so only because the Lazylanders decided voluntarily that it be so, via a decision made of and by the Lazylanders. The Bureaucracians do not presume to govern the Lazylanders.

The situation is analogous to the case of two individuals where one individual makes decisions about his life and the other individual voluntarily adopts the maxim to copy all the decisions of the first individual. Assume the first individual decides between buying a red hat or a blue one and the second has a preference for buying the blue hat but would buy the red one if the first individual decided so. It seems clear that the first individual does not have to take into account the preference of the second individual. The first individual is just exercising his autonomy and not interfering with the autonomy of the second individual.

$\mathrm{ASP}_{\mathrm{L}}$ yields the wrong answer in Bureaucracia and Lazyland. Since Lazyland's Law of Traffic Rules makes it the case that the people of Lazyland are legally bound by Bureaucracia's Traffic Law, $\mathrm{ASP}_{\mathrm{L}}$ implies that the Lazylanders should be entitled to participate in Bureaucracia's decision about adding a speed limit to its Traffic Law. $\mathrm{ASP}_{\mathrm{L}}$ fails to recognize that the decision in question is part of the self-government of the people of Bureaucracia.

Let us now consider three objections. The first objection denies that Bureaucracia's Traffic Law is legally binding for the Lazylanders. What is binding for the Lazylanders is only Lazyland's Law of Traffic Rules, so the objection goes, whereas Bureaucracia's Traffic Law is only needed to ascertain the contents of Lazyland's Law of Traffic Rules. ${ }^{16}$

This objection fails because it confuses the sources of law and the sources of legal interpretation. According to the objection, Bureaucracia's Traffic Law is not legally binding for the Lazylanders but merely a source of legal interpretation: the Traffic Law only serves to ascertain the contents of Lazyland's Law of Traffic Rules. From a legal perspective, however, it is clear that the legal norms referred to in legal norms of referral are legally binding (assuming that the legal norms of referral are themselves legally binding). Accordingly, there simply is no question for legal practitioners in Lazyland as to whether Bureaucracia's Traffic Law is legally binding: of course, it is-in virtue of Lazyland's Law of Traffic Rules, that

\footnotetext{
14 Beckman (2009) and López-Guerra (2014) discuss the cases of children, mentally impaired persons and felons in the context of BP.

15 Or so I claim, see the objections below.

16 This objection was raised by Gustaf Arrhenius.
} 
is: because Lazyland's Law of Traffic Rules is legally binding in Lazyland and states that Bureaucracia's Traffic Law is legally binding there, too. ${ }^{17}$

According to the second objection, the claim that both the Law of Traffic Rules and the Traffic Law are legally binding in Lazyland contradicts the logic of norms. The objection can be spelled out in different ways, depending on one's understanding of legal norms and the logic of norms in general. A natural way to spell out the objection goes as follows. Assume that Bureaucracia changes its Traffic Law by including a speed limit on highways. If a Lazylander drives too fast, she has violated only one legal norm-a norm against speeding. However, by claiming that both Bureaucracia's Traffic Law and Lazyland's Law of Traffic Rules are legally binding in Lazyland, I seem to be committed to the claim that the Lazylander has violated two legal norms. ${ }^{18}$

A head-on response to the objection consists in insisting that the speeding Lazylander has violated two legal norms. By claiming that the speeding Lazylander has violated only one legal norm, the objection seems to presuppose that legal norms are imperatives: the Lazylander is certainly addressed only by one legal imperative'don't drive faster than ... on highways!'-and if legal norms are imperatives, then the Lazylander has violated only one legal norm. However, the presupposition that legal norms are imperatives is problematic. After all, there are many legal regulations-think of H. L. A. Hart's 'secondary rules'-that are commonly labelled 'legal norms' even though they do not seem to be imperatives. Moreover, the view that the speeding Lazylander has violated two legal norms is compatible with the position that she has disobeyed only one legal imperative: one can just add that the two legal norms violated by the Lazylander-Bureaucracia's Traffic Law and Lazyland's Law of Traffic Rules-together entail the legal imperative not to drive faster than ... on highways.

However, it is doubtful if the objection succeeds even if we assume that legal norms are imperatives and that the speeding Lazylander has violated only one legal norm. Given these assumptions, we still have to get clear on which legal norm has been violated by the Lazylander. On the face of it, it cannot be Lazyland's Law of Traffic Rules by itself, because this law does not say anything about speed limits on highways, but merely states that Bureaucracia's Traffic Law is legally binding in Lazyland. Two other candidate legal norms are more promising. The first candidate is Bureaucracia's Traffic Law, which can be understood as a self-standing imperative ('don't drive faster than... on highways!'). Of course, the Traffic Law does not by itself apply to Lazylanders. However, the Traffic Law does apply to Lazylanders because Lazyland's Law of Traffic Rules says so. ${ }^{19}$ The second candidate

\footnotetext{
17 It might be worth mentioning in this context that the legal bindingness of norms is not a matter of degree: a norm is either legally binding or it is not, period. Hence, the Traffic Law is not legally binding to a lesser degree in Lazyland than the Law of Traffic Rules.

18 Thanks to an anonymous reviewer for this criticism.

19 Is Lazyland's Law of Traffic Rules a legal norm, i.e. an imperative, on this suggestion? And if so, who is addressed by it? These questions raise doubts about the proposal in question, but they are irrelevant in our context. Recall that I assume in this part of my response to the second objection, for the sake of argument, the problematic claim that is presupposed by the second objection: that legal norms are imperatives. This claim does not only have problems with legal norms of referral but with what H. L. A. Hart
} 
is not codified in a single law but is the conjunction of Bureaucracia's Traffic Law and Lazyland's Law of Traffic Rules. The Traffic Law and the Law of Traffic Rules can each be considered incomplete legal norms while they together form a complete legal norm. Here, the conjunction is to be understood as an imperative in the following way: imperatives are, roughly, commands to do something that are addressed to somebody. Bureaucracia's Traffic Law states one part of an imperative-viz. which behaviour is commanded-and Lazyland's Law of Traffic Rules states (part of) another part-viz. who is addressed.

Let us turn to the third objection, which concerns the best understanding of $\mathrm{ASP}_{\mathrm{L}}$. Advocates of $\mathrm{ASP}_{\mathrm{L}}$ might point out that the Lazylanders are bound only indirectly by Bureaucracia's law, namely via the law of Lazyland, and argue that $\mathrm{ASP}_{\mathrm{L}}$ is meant to refer only to decisions that are directly binding for persons. $\mathrm{ASP}_{\mathrm{L}}$ would then not imply that the Lazylanders should be entitled to participate in the decision about Bureaucracia's Traffic Law.

This suggestion fails because many legal norms are binding only indirectly but all of them need democratic authorization. If a judge pronounces a sentence, for example, then the sentence is a legal norm that is valid only in virtue of another legal norm that empowers the judge to pronounce judgment. However, the sentence is of course made in the name of the people and democracy requires an uninterrupted chain of democratic authorization that connects the judge's sentence via the empowering norm all the way up to the legislature, which is either identical with or, in representative democracies, authorized by the people. Hence, $\mathrm{ASP}_{\mathrm{L}}$ should be understood as implying that legal norms require participation of those people who are subjected to those norms even if the norms are binding only indirectly.

A note on what I mean by 'authorized by the people' in the foregoing paragraph. Democracy is self-government: government of the people and by the (same) people. Public officials participate in governing the people. This means that public officials must be authorized to represent the people. This authorization, in democracies, happens in elections. $^{20}$

Here is a possible reply to my response to the third objection. According to my response, $\mathrm{ASP}_{\mathrm{L}}$ applies also to decisions that are indirectly binding but, as in the case of the judge, $\mathrm{ASP}_{\mathrm{L}}$ can be satisfied through an uninterrupted chain of democratic authorization by the people and does not require direct participation of the

\footnotetext{
Footnote 19 (continued)

called secondary rules in general. Given that I accept the claim only for the sake of argument, it is not on me to defend the claim or to explain how the claim can account for legal regulations that do not seem to be imperatives.

${ }^{20}$ A critic might worry that the ideal of self-government is committed to the rejection of certain views within democratic theory-views, for example, regarding the nature of democratic representation and regarding the justification of democracy. I have a twofold response. Firstly, it is not clear that the ideal has such commitments-it is on the critic to show which views exactly and why would be ruled out by the ideal. Secondly, insofar as the ideal of self-government does rule out certain views within democratic theory, one would have to adjudicate between the ideal of self-government and the views that contradict the ideal. Should we dismiss the ideal or the views that are at odds with the ideal? My tendency would be to stick to the ideal because I think that the claim that democracy is self-government by the people is a conceptual truth. Thanks to anonymous reviewers for pressing me on these issues.
} 
people. Now, does it not follow from this response that the Bureaucracians (analogously to the judge) can be considered authorized to make decisions that are indirectly binding for the Lazylanders? If so, then $\mathrm{ASP}_{\mathrm{L}}$ would not imply that the Lazylanders should be entitled to participate directly in the decision on Bureaucracia's Traffic Law. For the Lazylanders would have authorized the Bureaucracians to make that decision without the direct participation of the Lazylanders. ${ }^{21}$

There are three related problems with this reply. First of all, the reply assumes that Lazyland's Law of Traffic Rules is not just a legal norm of referral but (also) an authorizing norm, which empowers the Bureaucracians. On the face of it, this assumption is problematic because authorizing norms and norms of referral are different kinds of norms from a legal point of view, and the Law of Traffic Rules does not seem to be an authorizing norm but a norm of referral. The Law of Traffic Rules does not seem to be an authorizing norm for two reasons. On the one hand, the contents of the Law of Traffic Rules are relatively 'meagre', in particular, the Law of Traffic Rules does not specify any rights or duties of the allegedly authorized persons - the Law of Traffic Rules merely states that the Traffic Law is valid in Lazyland. On the other hand, while Lazyland lacks jurisdiction over Bureaucracia, normally persons who are legally authorized can also be held legally responsible (to ensure, in particular, that the authorized persons do not abuse their powers).

Secondly, if we assumed that the Law of Traffic Rules is an authorizing norm, then the Law of Traffic Rules would be more problematic from a democratic point of view than it seems in fact to be. For while the judge is merely authorized to pronounce judgment on the basis of existing laws, the Bureaucracians would in effect be authorized to make laws that are binding for the Lazylanders. (Of course, the laws made by the Bureaucracians would have to be incorporated into the Traffic Law, but otherwise there would be no restrictions.) Authorizations to make laws, which would be present in the case under consideration if the reply were correct, require elections of representatives. But the Bureaucracians are not elected as representatives by the Lazylanders.

Thirdly, even if the Law of Traffic Rules were meant to authorize the Bureaucracians to make traffic laws for the Lazylanders, the Law of Traffic Rules could be invalid as an authorizing norm. It could be invalid, for example, because there might be constitutional requirements for authorizing norms in Lazyland that are not met by the Law of Traffic Rules. However, the Law of Traffic Rules would then apparently nonetheless be valid as a legal norm of referral-unless we make the questionbegging assumption that a legal norm of referral just is an authorizing norm. (This assumption would not only be question-begging but also seems to be false; see the first two points of my response to the reply.) But if the Law of Traffic Rules is valid as a norm of referral and invalid as an authorizing norm, then we are again faced with the problem raised by the case of Bureaucracia and Lazyland-the reply then does not help the defender of $\mathrm{ASP}_{\mathrm{L}}$.

In sum, $\mathrm{ASP}_{\mathrm{L}}$ delivers implausible-viz. over-inclusive-verdicts in Bureaucracia and Lazyland and in structurally similar cases that involve legal norms of

21 Thanks to an anonymous reviewer for this reply. 
referral. The verdicts are implausible in that they contradict widespread intuitive judgements. These judgements are not mere intuitions but cohere with other relevant beliefs, as required by the method of reflective equilibrium, in that the judgements can be based on the ideal of democracy as self-government: government of the people by the same people. $\mathrm{ASP}_{\mathrm{L}}$ is, hence, at odds with our considered judgements regarding democratic inclusion.

\section{Against $\mathrm{ASP}_{\mathrm{C}}$}

This section argues that $\mathrm{ASP}_{\mathrm{C}}$ is extensionally inadequate. To this end, I will introduce a modified version of Bureaucracia and Lazyland. But let us first consider what $\mathrm{ASP}_{\mathrm{C}}$ implies with regard to the original case.

Recall that, according to $\mathrm{ASP}_{\mathrm{C}}$, a person should be entitled to participate in a democratic decision if and only if the person is exposed to coercion by the state that implements the decision. Now, one might argue as follows: 'Since the state of Lazyland does not only implement Lazyland's Law of Traffic Rules in Lazyland but, by doing this, the state of Lazyland also implements Bureaucracia's Traffic Law, $\mathrm{ASP}_{\mathrm{C}}$ implies that the Lazylanders should be entitled to participate in the decision about Bureaucracia's Traffic Law'. If $\mathrm{ASP}_{\mathrm{C}}$ is understood in this way, $\mathrm{ASP}_{\mathrm{C}}$ shares the extensional inadequacy that, as I have argued in the Against $\mathrm{ASP}_{\mathrm{L}}$ section, accrues to $\mathrm{ASP}_{\mathrm{L}}$.

However, $\mathrm{ASP}_{\mathrm{C}}$ can be interpreted in a more charitable way. On

\section{The charitable interpretation}

A state implements a decision only if the decision has been made by that state. $^{22}$

Bureaucracia's Traffic Law has not been made by the state of Lazyland, but by the state of Bureaucracia. For this reason, according to the charitable interpretation of $\mathrm{ASP}_{\mathrm{C}}$, Lazyland does not implement Bureaucracia's Traffic Law but only Lazyland's Law of Traffic Rules. Bureaucracia's Traffic Law is, rather, implemented by the state of Bureaucracia, which, however, is not active in Lazyland and hence does not expose the Lazylanders to coercion.

In short, the charitable interpretation of $\mathrm{ASP}_{\mathrm{C}}$ implies that the state of Lazyland, while generally exposing the Lazylanders to coercion, does not implement Bureaucracia's Traffic Law, and the state of Bureaucracia, though implementing Bureaucracia's Traffic Law, does not expose the Lazylanders to coercion. Consequently, the Lazylanders are not exposed to coercion by the state that implements Bureaucracia's Traffic Law. Therefore, $\mathrm{ASP}_{\mathrm{C}}$ implies that the Lazylanders should not be entitled to

\footnotetext{
22 Strictly speaking, it is the demos of a state or state organs that decide what the state does. However, we normally attribute these decisions to the state. I think that this is unproblematic and will ignore the issue in what follows. However, people who disagree can understand the phrase that a 'decision has been made by a state' in a metaphorical way and focus instead on our practice of imputing the decision to the state.
} 
participate in the decision about Bureaucracia's Traffic Law. The case of Bureaucracia and Lazyland, hence, does not show that $\mathrm{ASP}_{\mathrm{C}}$ is extensionally inadequate. ${ }^{23}$

However, $\mathrm{ASP}_{\mathrm{C}}$ gets it wrong in the following case:

\section{Bureaucracia and Lazyland (Extended Version)}

[As in the original case:] Lazyland's Law of Traffic Rules states that Bureaucracia's Traffic Law is valid in Lazyland. The Bureaucracians are going to make a democratic decision about a speed limit on highways. The Lazylanders would like to participate in the decision and vote against the speed limit. [In addition to the original case:] Bureaucracia and Lazyland have agreed on an arrangement of international administrative assistance according to which Bureaucracian police officers patrol the highways in Lazyland and fine Lazylanders who do not abide by Bureaucracia's Traffic Law. ${ }^{24}$

In Bureaucracia and Lazyland (Extended Version), $\mathrm{ASP}_{\mathrm{C}}$ implies-also on the charitable interpretation - that the Lazylanders should be entitled to participate in Bureaucracia's decision about its Traffic Law. Like the original case of Bureaucracia and Lazyland, the case of Bureaucracia and Lazyland (Extended Version) has it that Bureaucracia's Traffic Law is valid in Lazyland in virtue of Lazyland's Law of Traffic Rules. In addition, though, in Bureaucracia and Lazyland (Extended Version), Bureaucracia provides international administrative assistance to Lazyland in virtue of which the Lazylanders are exposed to coercion by the state of Bureaucracia, which implements the law in Lazyland. The above-mentioned charitable interpretation of $\mathrm{ASP}_{\mathrm{C}}$, according to which a state implements a decision only if the decision has been made by that state, is not relevant here, because Bureaucracia's Traffic Law has been made by (or can be imputed to) the state of Bureaucracia.

One might object that the state of Bureaucracia does not implement Bureaucracia's Traffic Law in Lazyland by policing Lazyland's highways. Rather, the state of Bureaucracia, so the objection goes, implements Lazyland's Law of Traffic Rules in Lazyland. If the objection holds, $\mathrm{ASP}_{\mathrm{C}}$ implies that the Lazylanders should not be entitled to participate in the decision about Bureaucracia's Traffic Law

The objection fails. Let us assume, as stated in the objection, that Bureaucracia implements the Law of Traffic Rules in Lazyland. If so, it still seems true that Bureaucracia also implements the Traffic Law in Lazyland. This seems true because the Bureaucracian police officers, when patrolling the highways of Lazyland, look up the conditions under which they ought to fine somebody, such as speed limits, in Bureaucracia's Traffic Law. This behaviour-looking up of conditions and legal consequences in a law and acting so as to bring about the legal consequences-can naturally be called implementing the law.

\footnotetext{
23 Notice that a similar move is not open to $\mathrm{ASP}_{\mathrm{L}}$. The move is open to $\mathrm{ASP}_{\mathrm{C}}$ because $\mathrm{ASP}_{\mathrm{C}}$ can distinguish between the coercing entity (state), on the one hand, and the group of persons that make a democratic decision (demos), on the other. Coercing entities thus figure as a third element in $\mathrm{ASP}_{\mathrm{C}}$, which can be used to block certain mappings between persons and democratic decisions. Since $\operatorname{ASP}_{\mathrm{L}}$ does not contain a third element, proponents of $\mathrm{ASP}_{\mathrm{L}}$ cannot make a similar move.

${ }^{24}$ For real-life cases of international administrative assistance, see, e.g., Damian (2009).
} 
However, let us choose a phrase that is neutral with regard to the objection and call the behaviour applying the law. The police officers apply the Traffic Law in Lazyland. Now, in order to deny that the state of Bureaucracia implements the Traffic Law while affirming that the state of Bureaucracia implements the Law of Traffic Rules, proponents of the objection must accept something like the following Implementation Principle — a position about which legal norm is implemented by a state that applies a legal norm:

IP

For any two norms $n_{1}$ and $n_{2}$ of public law, if $n_{1}$ is legally binding in virtue of $\mathrm{n}_{2}$, then a state that applies $\mathrm{n}_{1}$ is thereby implementing $\mathrm{n}_{2}$ and not implementing $\mathrm{n}_{1}$.

I have explained in the Against $\mathrm{ASP}_{\mathrm{L}}$ section that, from a legal perspective, Bureaucracia's Traffic Law is legally binding in Lazyland in virtue of Lazyland's Law of Traffic Rules. ${ }^{25}$ If IP is correct, then the state of Bureaucracia implements the Law of Traffic Rules in Lazyland and does not implement its Traffic Law there.

However, proponents of $\mathrm{ASP}_{\mathrm{C}}$ cannot accept IP because otherwise $\mathrm{ASP}_{\mathrm{C}}$ is faced with severe problems. To illustrate, assume Bureaucracia has a constitution, which embodies fundamental principles that determine the general conditions under which laws are valid. From a legal point of view, Bureaucracia's Traffic Law is legally binding in virtue of Bureaucracia's constitution. But this means that, according to IP, when Bureaucracian police officers apply the Traffic Law in Bureaucracia, they are thereby implementing only Bureaucracia's constitution but not the Traffic Law. Consequentially, on IP, $\mathrm{ASP}_{\mathrm{C}}$ implies that the Bureaucracians should not be entitled to participate in the decision about changing Bureaucracia's Traffic Law. That cannot be right. Proponents of $\mathrm{ASP}_{\mathrm{C}}$ must reject IP.

The upshot is that with regard to Bureaucracia and Lazyland (Extended Version), $\mathrm{ASP}_{\mathrm{C}}$ implies that the Lazylanders should be entitled to participate in the democratic decision about Bureaucracia's Traffic Law. But just like $\mathrm{ASP}_{\mathrm{L}}$ 's verdict concerning Bureaucracia and Lazyland, and for similar reasons, $\mathrm{ASP}_{\mathrm{C}}$ 's verdict concerning Bureaucracia and Lazyland (Extended Version) is implausible. The Lazylanders should not be entitled to participate in the decision about Bureaucracia's Traffic Law. The decision about the Traffic Law is an instance of government of and by the people of Bureaucracia. It is not the business of the Lazylanders how Bureaucracians regulate their traffic. The Bureaucracians do not presume to govern the Lazylanders. Rather, the Lazylanders are bound by Bureaucracian law and exposed to coercion by Bureaucracian police only because the Lazylanders themselves decided so.

This is not to say that the decisions of the Lazylanders are completely unproblematic as far as the ideal of democracy is concerned. It can be argued that, by adopting

\footnotetext{
25 Recall that I am making a legal claim here. A lawyer, when asked if Bureaucracia's Traffic Law is legally binding in Lazyland, would answer: 'Sure, the Traffic Law is binding in Lazyland because Lazyland's Law of Traffic Rules states that this is so'. Notice also that my claim is compatible with the claim that Bureaucracia's Traffic Law is legally binding in Lazyland in virtue of the decision of Lazyland to adopt Bureaucracia's Law of Traffic Rules: this decision finds expression in Lazyland's Law of Traffic Rules. Thanks to an anonymous reviewer for pressing me on these issues.
} 
foreign laws and letting foreign powers enforce these laws, the Lazylanders suffer losses in terms of democracy. Such an argument seems particularly forceful if democracy is based on the (contested) doctrine of popular sovereignty but can perhaps also be upheld without adopting this doctrine. ${ }^{26}$

However, the possible democratic losses do not justify the claim that the Lazylanders should be entitled to participate in the decision about Bureaucracia's Traffic Law. If they were so entitled, we would face a constellation in which the governed (Bureaucracians) would be different from the governing (Bureaucracians and Lazylanders) as far as the Traffic Law is concerned. This would be a clear violation of the democratic ideal of self-government.

Moreover, the possible losses in terms of democracy that the Lazylanders might incur in virtue of the Law of Traffic Rules and the international administrative assistance would be self-imposed. This cannot possibly justify limiting the democracy of the Bureaucracians by letting the Lazylanders participate in the decision about the Traffic Law. Rather, the possible losses would need to be remedied by the Lazylanders themselves. And this could be done by abandoning the Law of Traffic Rules and by cancelling the agreement about international administrative assistance. It is noteworthy, in this context, that while the Lazylanders should not be entitled to participate in the decision about Bureaucracia's Traffic Law, they should be so entitled with regard to decisions about Lazyland's Law of Traffic Rules and about Lazyland's consent to the agreement with Bureaucracia about international administrative assistance.

To sum up, $\mathrm{ASP}_{\mathrm{C}}$ is just as over-inclusive with regard to Bureaucracia and Lazyland as $\mathrm{ASP}_{\mathrm{L}}$, unless $\mathrm{ASP}_{\mathrm{C}}$ is charitably interpreted such that a state implements a decision only if the decision has been made by (or can be imputed to) that state. ${ }^{27}$ But even charitably interpreted, $\mathrm{ASP}_{\mathrm{C}}$ is over-inclusive with regard to Bureaucracia and Lazyland (Extended Version) and structurally analogous cases that involve international administrative assistance. The intuitively correct judgement is that, pace $\mathrm{ASP}_{\mathrm{C}}$, the Lazylanders should not be entitled to participate in the decision about Bureaucracia's Traffic Law. This judgement coheres with, and can be based on, the ideal of democracy as self-government: government of the people by the same people. This shows that $\mathrm{ASP}_{\mathrm{C}}$ is extensionally inadequate in that its implications regarding certain cases of democratic inclusion contradict our considered judgements.

\footnotetext{
${ }^{26}$ According to the doctrine of popular sovereignty, the people's unified will is the supreme authority in the state. See, e.g., Espejo (2015).

${ }^{27} \mathrm{ASP}_{\mathrm{C}}$ might be less inclusive than $\mathrm{ASP}_{\mathrm{L}}$, as mentioned in the Extensional Adequacy and ASP section, if a person can be legally bound without being exposed to coercion. But then $\mathrm{ASP}_{\mathrm{C}}$ runs into other problems, see Goodin (2016).
} 


\section{ASP*}

I have argued that $\mathrm{ASP}_{\mathrm{L}}$ and $\mathrm{ASP}_{\mathrm{C}}$ yield over-inclusive verdicts in Bureaucracia and Lazyland or in Bureaucracia and Lazyland (Extended Version). This section deals with alternative formulations of the All-Subjected Principle and its variants:

$A S P^{*}$

A person should be entitled to participate in a democratic decision if and only if the decision is made by a state to whose decisions the person is normally subject.

$A S P_{L}^{*}$

A person should be entitled to participate in a democratic decision if and only if the decision is made by a state whose decisions are normally legally binding for the person.

$A S P_{C} *$

A person should be entitled to participate in a democratic decision if and only if the decision is made by a state that normally implements decisions in ways that normally expose the person to coercion.

ASP* involves what we can label the Normality Condition: that a person is normally subject to the decisions made by a state. The Normality Condition is a necessary and sufficient condition, according to ASP*, for when a person should be entitled to participate in a democratic decision. $\mathrm{ASP}_{\mathrm{C}}{ }^{*}$ and $\mathrm{ASP}_{\mathrm{L}}{ }^{*}$ spell out the Normality Condition in terms of legal bindingness or coercion, respectively.

$\mathrm{ASP}^{*}, \mathrm{ASP}_{\mathrm{L}} *$ and $\mathrm{ASP}_{\mathrm{C}} *$ do not imply the implausible verdicts that $\mathrm{ASP}, \mathrm{ASP}_{\mathrm{L}}$ and $\mathrm{ASP}_{\mathrm{C}}$ imply in the cases presented in the two foregoing sections. According to $\mathrm{ASP}_{\mathrm{L}}{ }^{*}$, the Lazylanders should not be entitled to participate in the decision about Bureaucracia's Traffic Law in Bureaucracia and Lazyland, because the Lazylanders are normally not legally bound by the decisions made by Bureaucracia. Likewise, with regard to Bureaucracia and Lazyland (Extended Version), $\mathrm{ASP}_{\mathrm{C}}$ * implies that the Lazylanders should not be entitled to participate in the decision about Bureaucracia's Traffic Law because the Lazylanders are normally not exposed to coercion by implementations performed by Bureaucracia.

Notice that the phrase 'normally' in $\mathrm{ASP}^{*}, \mathrm{ASP}_{\mathrm{L}}$ * and $\mathrm{ASP}_{\mathrm{C}}$ * could be replaced by something like 'systematically', 'by and large', 'regularly' or 'in most cases'. Perhaps defenders of $\mathrm{ASP}_{\mathrm{L}}$ * can alternatively focus on who is regularly legally bound by a state's decisions in virtue of the state's constitution. Anyhow, since none of these alternatives will impact the response that I present below, I will keep things simple by focusing on 'normally' and ignore alternative qualifiers.

It is often not clear, I think, whether proponents of the All-Subjected Principle endorse ASP or ASP*. Notice, however, that Erman explicitly endorses a principle along the lines of ASP*, according to which 'all those who are systematically and over time subjected to the exercise of political power (authority) and to its laws, political decisions and rules, should systematically and over time have an equal 
influence in the decision-making' (Erman 2014, p. 539). She explicitly states that 'the "systematically and over time" requirement suggests an institutional approach to democracy, stating that [democratic] participation does not concern each and every decision but the complete set of decisions over time' (Erman 2014, p. 539, footnote omitted; cf. Owen 2012).

I submit that, although $\mathrm{ASP}^{*}, \mathrm{ASP}_{\mathrm{L}} *$ and $\mathrm{ASP}_{\mathrm{C}} *$ avoid the problems that I presented in the two foregoing sections, $\mathrm{ASP}, \mathrm{ASP}_{\mathrm{L}}$ and $\mathrm{ASP}_{\mathrm{C}}$ are on balance to be preferred over $\mathrm{ASP}^{*}, \mathrm{ASP}_{\mathrm{L}} *$ and $\mathrm{ASP}_{\mathrm{C}} *$. To see why, we have to consider again why the All-Subjected Principle is attractive in the first place. Recall that the democratic ideal is the ideal of self-government: government of the people by the same people. This ideal can be justified in terms of autonomy, equality and fairness. ${ }^{28}$ For example, Dahl writes that '[b]inding decisions are to be made only by persons that are subject to the decisions [...] No lawmaker is, in the familiar expression, above the law. The assumption rests on the elementary principle of fairness that laws cannot be rightfully imposed on other persons by persons who are not themselves obliged to obey those laws. Moreover, [...] this assumption [...] is necessary to self-determination; for laws and rules imposed by an outsider would violate the self-determination of all those subject to the laws' (Dahl 1989, pp. 107-108). And Miller maintains that 'the normal effect of coercion is to undermine personal autonomy [...] It is hard to see how a democracy could be legitimate if it prevents outsiders from enjoying one of the conditions it is designed to protect' (Miller 2009, p. 214). Although Erman, as mentioned, endorses the Normality Condition, she also holds that ' $[w]$ hat distinguishes democracy from other forms of government, such as dictatorship, is that it has components that express and secure some form of political equality. [...] what is of concern here is a specific conception of equality, according to which anyone who is in a specific sense affected by a political decision (or law) has an equal opportunity, secured through an equal right, to participate (directly or indirectly) in the decision about it' (Erman 2014, p. 536, footnote omitted). These considerations suggest that if a person is governed without participating in the government then this person suffers losses in terms of autonomy, equality or fairness. Likewise, if a person is participating in the government without being governed herself, then this arguably involves losses in terms of autonomy, equality or fairness for the governed.

How does the ideal of democracy as self-government speak for ASP, $\mathrm{ASP}_{\mathrm{L}}$ and $\mathrm{ASP}_{\mathrm{C}}$ and against $\mathrm{ASP}^{*}, \mathrm{ASP}_{\mathrm{L}} *$ and $\mathrm{ASP}_{\mathrm{C}} *$ ? The point is that $\mathrm{ASP}, \mathrm{ASP}_{\mathrm{L}}$ and $\mathrm{ASP}_{\mathrm{C}}$ attempt to track the relevant considerations of autonomy, equality and fairness whereas $\mathrm{ASP}^{*}, \mathrm{ASP}_{\mathrm{L}} *$ and $\mathrm{ASP}_{\mathrm{C}} *$ do not. Suppose a person is legally bound by a decision and exposed to coercion by the state that implements this decision while it is neither the case that this state's decisions are normally legally binding for the person nor that this state normally implements decisions in ways that expose the person to coercion. Considerations of autonomy, equality and fairness suggest, in line with $\mathrm{ASP}, \mathrm{ASP}_{\mathrm{L}}$ and $\mathrm{ASP}_{\mathrm{C}}$, that the person should be entitled to participate in the decision. But $\mathrm{ASP}^{*}, \mathrm{ASP}_{\mathrm{L}} *$ and $\mathrm{ASP}_{\mathrm{C}} *$ imply that she should not be so entitled. The Normality Condition entailed in $\mathrm{ASP}^{*}, \mathrm{ASP}_{\mathrm{L}}{ }^{*}$ and $\mathrm{ASP}_{\mathrm{C}}{ }^{*}$ fails as a

$\overline{28}$ For an overview on justifications of democracy, see Christiano (2018). 
necessary condition for when a person should be entitled to participate in a democratic decision.

How does my rejection of the Normality Condition relate to what I say about the cases in the two foregoing sections? There, I argued for the claim that the Lazylanders should not be entitled to participate in the decision about Bureaucracia's Traffic Law. And as mentioned at the beginning of this section, $\mathrm{ASP}^{*}, \mathrm{ASP}_{\mathrm{L}}{ }^{*}$ and $\mathrm{ASP}_{\mathrm{C}} *$ yield this claim. Am I contradicting myself? ${ }^{29}$

It is true that $\mathrm{ASP}^{*}, \mathrm{ASP}_{\mathrm{L}} *$ and $\mathrm{ASP}_{\mathrm{C}} *$ get the cases in the two foregoing sections right because they involve the Normality Condition. But this just means that they get the right answers in these cases for the wrong reasons. My arguments in the two foregoing sections for the claim that the Lazylanders should not be entitled to participate in the decision about Bureaucracia's Traffic Law are not based on the Normality Condition. Rather, I have pointed out that the claim is supported by widespread intuitive judgements which cohere with the democratic ideal of self-government. This ideal, as mentioned above, can itself be justified in terms of autonomy, equality and fairness.

To see that $\mathrm{ASP}^{*}, \mathrm{ASP}_{\mathrm{L}} *$ and $\mathrm{ASP}_{\mathrm{C}} *$ are at odds with the democratic ideal of self-government and its underlying considerations of autonomy, equality and fairness, we must not consider the cases presented in the foregoing sections but cases that lack the particular features of the cases considered in the foregoing sections: legal norms of referral and international administrative assistance. Assume, for example, that the Bureaucracians decide that their Traffic Law is legally binding in Lazyland and that the Bureaucracians send police officers who patrol the highways in Lazyland to implement the Traffic Law, while the Lazylanders do not issue relevant norms of referral or international administrative assistance. This would be impermissible from a democratic point of view because the Bureaucracian measures would qualify as government of the Lazylanders by the Bureaucracians and would violate considerations of autonomy, equality and fairness to the detriment of the Lazylanders. However, given that the Lazylanders would not normally be subject to the decisions by the Bureaucracians, $\mathrm{ASP}^{*}, \mathrm{ASP}_{\mathrm{L}}{ }^{*}$ and $\mathrm{ASP}_{\mathrm{C}}{ }^{*}$ get the wrong verdicts in this case (whereas $\mathrm{ASP}, \mathrm{ASP}_{\mathrm{L}}$ and $\mathrm{ASP}_{\mathrm{C}}$ get it right).

So, the Normality Condition fails as a necessary condition for when a person should be entitled to participate in a democratic decision. The Normality Condition also fails as a sufficient condition. Consider a state and a group of people for whom this state's decisions are normally legally binding and coercive. If the state makes a decision that does not affect these people in said ways but the people are nonetheless entitled to participate in the decision, as is sufficient for rights to democratic participation according to $\mathrm{ASP}^{*}, \mathrm{ASP}_{\mathrm{L}} *$ and $\mathrm{ASP}_{\mathrm{C}}{ }^{*}$, then this has costs in terms of autonomy, equality and fairness for those people who are legally bound by the decision in question and for whom the decision is coercive. $\mathrm{ASP}, \mathrm{ASP}_{\mathrm{L}}$ and $\mathrm{ASP}_{\mathrm{C}}$, on the other hand, provide the correct result. To give an example, take a federal state whose decisions are normally legally binding in all member states and expose the citizens there to coercion. If there is an exceptional law by the federal state that is

29 Thanks to an anonymous reviewer for pointing out this problem. 
not legally binding in one of the member states and does not expose the citizens in that member state to coercion, then the citizens of that member state should not be entitled to participate in that law.

To sum up, proponents of the All-Subjected Principle can avoid the criticisms I have presented in this paper by rejecting $\mathrm{ASP}, \mathrm{ASP}_{\mathrm{L}}$ and $\mathrm{ASP}_{\mathrm{C}}$ and endorsing $\mathrm{ASP}^{*}$, $\mathrm{ASP}_{\mathrm{L}} *$ and $\mathrm{ASP}_{\mathrm{C}} *$ instead. But the democratic ideal of self-government-and the underlying considerations of autonomy, equality and fairness-support ASP, $\mathrm{ASP}_{\mathrm{L}}$ and $\mathrm{ASP}_{\mathrm{C}}$ better than $\mathrm{ASP}^{*}, \mathrm{ASP}_{\mathrm{L}} *$ and $\mathrm{ASP}_{\mathrm{C}} *$.

\section{Conclusion}

In this paper, I have argued that $\mathrm{ASP}_{\mathrm{L}}$ and $\mathrm{ASP}_{\mathrm{C}}$, the two versions of ASP that can be found in the literature, are extensionally inadequate. I have also argued against $\mathrm{ASP}^{*}, \mathrm{ASP}_{\mathrm{L}} *$ and $\mathrm{ASP}_{\mathrm{C}} *$ by critiquing the Normality Condition. If my arguments are correct, we have strong reasons for rejecting the All-Subjected Principle-at least unless proponents of the All-Subjected Principle come up with a better version of their principle.

Acknowledgements Open Access funding provided by Projekt DEAL. Previous versions of this paper have been presented at the Institute for Futures Studies (Stockholm) and at the Johannes Gutenberg-Universität Mainz. I would like to thank the audiences. Special thanks go to Kim Angell, Gustaf Arrhenius, Ludvig Beckman, Andreas Bengtson, Paul Bowman, Ralf Busse, Tim Campbell, Eva Erman, Eliav Lieblich, Cornelius Menke, Julia Mosquera, Christian Neuhäuser, Peter Schaber, Rudolf Schüßler, Ashwini Vasanthakumar, and two anonymous reviewers. The research was funded by the Alexander von Humboldt Foundation, the Marianne and Marcus Wallenberg Foundation, and the Swedish Research Council.

Open Access This article is licensed under a Creative Commons Attribution 4.0 International License, which permits use, sharing, adaptation, distribution and reproduction in any medium or format, as long as you give appropriate credit to the original author(s) and the source, provide a link to the Creative Commons licence, and indicate if changes were made. The images or other third party material in this article are included in the article's Creative Commons licence, unless indicated otherwise in a credit line to the material. If material is not included in the article's Creative Commons licence and your intended use is not permitted by statutory regulation or exceeds the permitted use, you will need to obtain permission directly from the copyright holder. To view a copy of this licence, visit http://creativecommons.org/licen ses/by/4.0/.

\section{References}

Abizadeh, Arash. 2008. Democratic theory and border coercion: No right to unilaterally control your own borders. Political Theory 36: 37-65.

Abizadeh, Arash. 2010. Democratic legitimacy and state coercion: A reply to David Miller. Political Theory $38: 121-130$.

Abizadeh, Arash. 2012. On the demos and its kin: Nationalism, democracy, and the boundary problem. American Political Science Review 106: 867-882.

Agné, Hans. 2010. Why democracy must be global: Self-founding and democratic intervention. International Theory 2(3).

Andrić, Vuko. 2017. How do affected interests support global democracy? Journal of Global Ethics 13(3): 264-278. 
Arrhenius, Gustaf. 2005. The boundary problem in democratic theory. In Democracy Unbound: Basic Explorations I, ed. Folke Tersman, 14-29. Stockholm: Filosofiska institutionen, Stockholms Universitet.

Arrhenius, Gustaf. 2018. The democratic boundary problem reconsidered. Ethics, Polity \& Society 1: 89-122.

Arrhenius, Gustaf. 2019. Democracy for the 21th century: Research challenges. In: Sociology Looks at the Twenty-first Century: From Local Universalism to Global Contextualism, ed. S. Randeria and B. Wittrock, chapter 10. Brill: Leiden and Boston.

Beckman, Ludvig. 2006. Citizenship and voting rights: Should resident aliens vote? Citizenship Studies 10: $153-165$.

Beckman, Ludvig. 2008. Democratic inclusion, law, and causes. Ratio Juris 21(3): 348-364.

Beckman, Ludvig. 2009. Frontiers of democracy. The right to vote and its limits. London: Palgrave Macmillan.

Beckman, Ludvig. 2013. Democracy and future generations. Should the unborn have a voice? In Spheres of Global Justice. Volume 1: Global Challenges to Liberal Democracy. Political Participation, Minorities and Migrations, ed. J.-Ch. Merle, 775-88. Dordrecht: Springer.

Beckman, Ludvig. 2014. The subjects of collectively binding decisions: Democratic inclusion and extraterritorial law. Ratio Juris 27: 252-270.

Brighouse, Harry, and Marc Fleurbaey. 2010. Democracy and proportionality. Journal of Political Philosophy 18: 137-155.

Campbell, Dennis. 1997. Enforcement of foreign judgements, 2nd edn. LLP Professional Publishing.

Christiano, Tom. 2018. Democracy. In The Stanford Encyclopedia of Philosophy (Fall 2018 Edition), ed. Edward N. Zalta. https://plato.stanford.edu/archives/fall2018/entries/democracy/.

Cohen, Carl. 1971. Democracy. Athens: University of Georgia Press.

Cohen, Joshua. 1998. Democracy and liberty. In Elster, ed. J. Deliberative Democracy, 185-231. Cambridge: Cambridge University Press.

Dahl, Robert A. 1970. After the revolution? Authority in a good society. New Haven, CT: Yale University Press.

Dahl, Robert A. 1989. Democracy and its critics. New Haven and London: Yale University Press.

Damian, Helmut. 2009. Mutual legal assistance in administrative matters. Max Planck Encyclopedia of Public International Law. Oxford University Press.

Daniels, Norman. 2018. Reflective equilibrium. The Stanford Encyclopedia of Philosophy (Fall 2018 Edition), ed. Edward N. Zalta. https://plato.stanford.edu/archives/fall2018/entries/reflective-equilibriu $\mathrm{m} /$.

Erman, Eva. 2014. The boundary problem and the ideal of democracy. Constellations 21: 535-546.

Espejo, Paulina Ochoa. 2015. Popular sovereignty. In The Encyclopedia of Political Thought, ed. Michael T. Gibbons. Hoboken, NJ: Wiley-Blackwell.

Goodin, Robert. 2007. Enfranchising all affected interests, and its alternatives. Philosophy \& Public Affairs 35: 40-68.

Goodin, Robert. 2016. Enfranchising all subjected, worldwide. International Theory 8: 365-389.

Habermas, Jürgen. 1998. Between facts and norms. Cambridge, MA: MIT Press.

List, Christian, and Mathias Koenig-Archibugi. 2010. Can there be a global demos? An agency-based approach. Philosophy \& Public Affairs 38: 76-110.

López-Guerra, Claudio. 2005. Should expatriates vote? Journal of Political Philosophy 13: 216-234.

López-Guerra, Claudio. 2014. Democracy and disenfranchisement: the morality of electoral exclusions. New York: Oxford University Press.

Miller, David. 2009. Democracy's domain. Philosophy \& Public Affairs 37: 201-228.

Miller, David. 2010. Why immigration controls are not coercive: A reply to Arash Abizadeh. Political Theory 38: 111-130.

Owen, David. 2012. Constituting the polity, constituting the demos: On the place of the all affected interests principle in democratic theory and in resolving the democratic boundary problem. Ethics \& Global Politics 5: 129-152.

Shapiro, Ian. 1999. Democratic justice. New Haven: Yale Univesity Press.

Shapiro, Ian. 2012. The moral foundations of politics. New Haven: Yale University Press.

Song, Sarah. 2012. The boundary problem in democratic theory: Why the demos should be bounded by the state. International Theory 4: 39-86.

Tännsjö, Torbjörn. 2007. Future people, the all affected principle, and the limits of the aggregation model of democracy. In Hommage à Wlodek Philosophical Papers Dedicated to Wlodek Rabinowicz, ed. T. 
Rønnow-Rasmussen, B. Petersson, J. Josefsson, and D. Egonsson. http://www.fil.lu.se/hommageawl odek.

Whelan, Frederick G. 1983. Democratic theory and the boundary problem. In Liberal Democracy, ed. J. R. Pennock and J. W. Chapman, 13-47. New York and London: New York University Press.

Young, Iris Marion. 2000. Inclusion and democracy. New York: Oxford University Press.

Publisher's Note Springer Nature remains neutral with regard to jurisdictional claims in published maps and institutional affiliations. 